\title{
CUIDADORES DE IDOSOS EM SITUAÇÃO DE PANDEMIA: REFLEXÕES SOBRE O CUIDAR E SER CUIDADO
}

Guiomar Virginia Vilela Assunção de Toledo Batello' ORCID: 0000-0003-3774-732X

Maria Sortênia Alves Guimarães'

ORCID: 0000-0001-6648-2530

Izabel Antonio de Carvalho Pereira" ORCID: 0000-0002-7840-0456

Monica Bandeira'

ORCID: 0000-0003-0043-0513

Daniella Pires Nunes"I ORCID: 0000-0002-4679-0373

'Universidade Federal do Tocantins. Palmas, Tocantins, Brasil.

"Departamento Cientifico de Enfermagem Gerontológica - ABEn/TO. Palmas, Tocantins, Brasil

"'Universidade Estadual de Campinas. Campinas, São Paulo, Brasil

\section{Autor Correspondente: Guiomar Virginia Vilela Assunção de Toledo Batello E-mail: guivilelatoledo@uft.edu.br}

Como citar:

Batello GVVAT, Guimarães MAS, Pereira IAC, Bandeira M, Nunes DP. Cuidadores de idosos em situação de pandemia: reflexões sobre o cuidar e ser cuidado. In: Santana RF (Org.). Enfermagem gerontologica no cuidado do idoso em tempos da COVID 19. 2.ed.rev. Brasilia, DF: Editora ABEn; 2020

p 20-24 (Serie Enfermagem e Pandemias, 2). https://doi.org/10.51234/aben.20.e02.c03

\section{INTRODUÇÃO}

O mundo tem presenciado a evolução da pandemia de Coronavírus Disease 2019 (COVID-19). É uma doença nova causada pelo novo coronavírus (SARS-CoV-2), sendo os primeiros casos detectados em dezembro de 2019, na China, e em fevereiro de 2020, no Brasil. Ainda não há evidências de tratamento específico para a COVID-19, no entanto, organizações internacionais e nacionais recomendam mudanças no estilo de vida para a contenção da propagação do vírus, a saber: higienização das mãos, etiqueta respiratória, uso de máscaras e o distanciamento social(1).

Estudos apontam a relação entre COVID-19 e idade, considerando a população idosa como o grupo mais vulnerável a apresentar condições clínicas mais severas e óbito. Tal fato justifica-se pela imunossenescência e condições crônicas preexistentes. Ademais, as consequências físicas e emocionais (sedentarismo, fragilidade, redução da mobilidade física, sintomas depressivos e ansiedade) decorrentes do distanciamento social podem predispor o idoso ao comprometimento funcional ${ }^{(2-3)}$.

Dados os riscos que os idosos enfrentam com a COVID-19 e a incapacidade funcional, também aumenta-se a demanda por cuidados. Camarano ${ }^{4}$ estimou que cerca de 3 milhões de idosos brasileiros apresentam comprometimento nas atividades básicas de vida diária que necessitam de cuidado informal. No que tange às características dos cuidadores, em sua maioria, são mulheres, cônjuge ou filhas, com baixa escolaridade, não remuneradas e que não foram capacitadas para exercer essa função ${ }^{(5,6,7)}$.

O ato de cuidar ainda é invisível socialmente, cuja provisão é realizada principalmente pela família que assiste o idoso nas demandas das atividades domésticas, de autocuidado e de apoio afetivo, emocional e financeiro ${ }^{(4,5,6)}$. Em tempos de pandemia, o cuidador continua a fornecer os cuidados à pessoa idosa, os quais podem ser intensificados em resposta à vulnerabilidade do idoso à COVID-19. 
Consequentemente, a tensão ocasionada por este cenário propicia ao cuidador desgaste físico, emocional e relacional que podem comprometer o ato de cuidar e o ser cuidado.

Neste contexto, a reflexão sobre o cuidador de idosos se faz necessária para instigar à comunidade, aos gestores e profissionais de saúde sobre a relevância do papel deste ator social no processo de cuidar, possibilitando maior visibilidade e reconhecimento. Ademais, possibilitará o reconhecimento da necessidade de suporte aos cuidadores na manutenção da sua saúde mental e física, em especial, durante a pandemia.

\section{OBJETIVO}

Refletir acerca dos cuidadores de idosos em tempos de pandemia de COVID-19, considerando o ato de cuidar e o ser cuidado.

\section{MÉTODOS}

Trata-se de uma análise teórico-reflexiva, construída a partir de leituras sobre a temática cuidador de idosos disponíveis em artigos científicos, em bases eletrônicas de dados. A produção teórica foi categorizada em três eixos: Cuidar de idosos no cenário de pandemia de COVID-19; abordagem reflexiva do cuidado e do cuidador; e, escuta qualificada como uma estratégia de cuidado ao cuidador: contribuição da enfermagem gerontológica.

\section{CUIDAR DE IDOSOS NO CENÁRIO DE PANDEMIA DE COVID-19}

Assumir o papel de cuidador, normalmente, ocorre por um acordo entre os membros familiares ou por falta de opções $^{(6)}$. O cuidar extrapola-se ao cuidado do corpo físico, mas exige a compreensão dos sentimentos, emoções e particularidades da pessoa cuidada a fim de manter ou melhorar a condição humana no processo de viver e morrer ${ }^{(8)}$.

A demanda por cuidador dependerá do nível de comprometimento funcional da pessoa idosa, que poderá assisti-lo de forma esporádica ou em tempo integral. Assim, em seu cotidiano, desempenhará funções voltadas para o auxílio nas atividades básicas de vida diária como o cuidado com a higiene, alimentação e locomoção. Também poderá assumir responsabilidades que perpassam por todo o ambiente doméstico e se exteriorizam aos serviços de saúde, bancos, supermercados e farmácias ${ }^{(9)}$.

Diante de situações de crise como a pandemia, o cuidado à pessoa idosa tornou-se redobrado por ser o grupo mais susceptível a complicações da COVID-19. Assim, as recomendações de segurança com idosos vão muito além das que já eram realizadas diariamente pelo cuidador. Faz-se necessário agora, que este intensifique os cuidados e a atenção para ações preventivas ligadas diretamente ao comportamento e à higiene. Ações que compreendem o uso de máscara, lavagem constante das mãos, desinfecção de produtos alimentares ou não, uso de álcool em gel, zelando também pelo respeito e mediando boas relações familiares ${ }^{(10)}$.

A recomendação do distanciamento social gerou alteração na rotina tanto dos idosos quanto dos cuidadores. Membros familiares que ocasionalmente, cuidavam de seus entes reorganizaram-se para fornecer apoio, como aquisição de alimentos, medicamentos ou outras necessidades ${ }^{(3)}$. Por outro lado, idosos mais dependentes e seus cuidadores ficaram restritos aos domicílios, não podendo receber visitas, e a sensação de solidão, desamparo e isolamento podem ser referidas por estes. Chama-se a atenção para a ênfase da participação da rede de apoio social para que estes sintam-se protegidos e acolhidos. Cita-se o uso das tecnologias para minimizar a distância física como realização de ligações telefônicas, chamadas de vídeos, envio de mensagens de texto ou e-mail.

Outra peculiaridade experienciada pelos idosos, nesse tempo de pandemia, tem sido a violência por parte dos membros familiares e cuidadores. O cuidador é, muitas vezes, o único a ter contato físico, como também o responsável por cuidar de forma integral, sem ter direito de escolha. Em consequência, o risco de violência contra o idoso pode-se agravar, ocorrendo de diferentes formas como: violência psicológica, física, negligência de cuidados, abandono emocional, abuso financeiro, que frequentemente é sofrida em silêncio e encoberta, devido à proximidade entre a vítima e o agressor, gerando medo de abandono e retaliações ${ }^{(11)}$. 
No entanto, o ato de cuidar é uma atividade laboral complexa e tão importante e ao mesmo tempo tão solitária. Pensar no cuidador é, por consequência, pensar no idoso, visto que este precisa estar bem para cuidar bem ${ }^{(12)}$.

\section{ABORDAGEM REFLEXIVA DO CUIDAR E DO CUIDADOR}

O olhar, o pensamento e o planejamento da família e da sociedade precisam incluir o cuidador não só como executor das ações planejadas, mas como sujeito principal na promoção e qualidade do cuidado. A visibilidade do papel do cuidador se faz urgente e necessária, por estar na "linha de frente anônima" no cuidado à pessoa idosa durante a pandemia.

Sentimentos restritos, queixas orgânicas desconhecidas para os outros, são o esboço desse cuidador que, sem perceber e sem ser percebido abre mão de sua vida para viver a vida de quem ele cuida. Por si o ato de cuidar gera eventos negativos como frustração, angústia, tristeza, sintomas depressivos e ansiedade, aumentando o estresse e a sobrecarga de cuidado ${ }^{(13)}$. Aproximadamente um terço dos cuidadores familiares refere sobrecarga que desmotiva e reduz o limiar de tolerância deste em relação a algumas situações, consequentemente expondo o idoso a cuidados impróprios ou escassos ${ }^{(6)}$.

Com circunstâncias resultantes da restrição social bem como a atenção redobrada para evitar o contágio pelo coronavírus, os cuidadores tendem a apresentar sobrecarga de trabalho, que é um dos desafios a serem enfrentados. Aliado a isso, visitas estão suspensas para a proteção do idoso, a responsabilidade se concentra em um só indivíduo, o que aumenta o risco de sua exaustão física e mental.

Diante desse cenário, oportunidades de socialização virtuais entre familiares e amigos são necessárias para acolher os cuidadores "fisicamente isolados". O reconhecimento da rede e o suporte recebido pelos cuidadores sinaliza o núcleo de proteção e ajuda ao provedor de cuidado, sendo a possível fonte para apoio emocional, psicológico e organizacional. O compartilhamento de experiências sociais deve ser fortalecido, e o cuidador sentir-se reconhecido, acolhido e apoiado.

\section{ESCUTA QUALIFICADA COMO UMA ESTRATÉGIA DE CUIDADO AO CUIDADOR: CONTRIBUIÇÃO DA ENFERMAGEM GERONTOLÓGICA}

Ao pensar na Enfermagem enquanto uma prática social, insere-se um olhar para o cuidado que vai além dos conhecimentos e das técnicas do modelo tradicional da ciência para se cuidar integralmente da pessoa. O cuidar integral é nutrir e alimentar o ser completo na sua singularidade, na perspectiva das diversas dimensões do viver. Diante disso, o enfermeiro deve reconhecer que o cuidador é um ser individual e coletivo, participante ativo de uma comunidade e deve-se respeitar seus significados e sua liberdade de ação e tomada de decisão em sua vida ${ }^{(14)}$.

Na perspectiva do cuidado humanizado, o respeito pela integridade, dignidade e autonomia da pessoa são preceitos da prática do cuidado integral. Assim, encontra-se o acolhimento que é uma das diretrizes da Política Nacional de Humanização (PNH) e é entendido como recebimento, acalento, acomodamento e agasalhamento, que permeia a atenção, o zelo, o bom trato e o olhar afetivo com o outro.

O acolhimento é uma 'tecnologia leve ou relacional', baseada na escuta qualificada. Nesse sentido, pode-se identificar claramente a articulação entre o acolhimento e a integralidade, no conceito de linhas de produção do cuidado. Assim, na perspectiva da integralidade do cuidado, a escuta qualificada possibilita um diálogo efetivo e afetivo, que propicia uma escuta sensível e acolhedora de forma integral que contribui para o estabelecimento do vínculo terapêutico, que a diversidade e a singularidade prevaleçam no encontro entre quem cuida e quem recebe o cuidado, além de reforçar o protagonismo do sujeito cuidador.

$\mathrm{O}$ acolhimento, por meio da escuta, possibilita ao cuidador que fale sobre seus anseios, dificuldades, sentimentos de angústia e sofrimento. Tal estratégia permite que ele sinta-se amparado e fortalecido para executar o cuidado, tomando para si o papel de protagonista da tarefa de cuidar. Frente à complexidade da 
pandemia de COVID-19, imprime-se a necessidade de ações de acolhimento e proteção à pessoa idosa bem como de seus cuidadores.

Diante disso, cita-se a experiência do Projeto Escuta Solidária, cuja proposta inicial realiza escuta qualificada de idosos e ocorre em três municípios brasileiros: Viçosa (MG), Palmas (TO) e Campinas (SP). O projeto foi idealizado por docente da Universidade Federal de Viçosa (UFV) e, posteriormente expandiu-se para a Universidade Federal do Tocantins (UFT) e Universidade Estadual de Campinas (UNICAMP), respeitando as especificidades regionais e demandas locais.

Destacam-se algumas particularidades deste projeto no município de Palmas (TO). Além dos idosos acoIhidos no projeto, os cuidadores de idosos acamados foram agregados na ação solidária. Atualmente, são acompanhados 32 cuidadores, sendo 81,3\% mulheres, 89,7\% familiares, com média de idade de 48,3 anos, de tempo de cuidado de 5,6 anos. Ademais, conta com o apoio da Secretaria Municipal de Saúde que mobilizou várias ações para apoiar tanto os idosos quanto os cuidares, destaca-se a inclusão dos cuidadores de idosos acamados na agenda prioritária da vacina da gripe.

Essas ações, de forma integrada, fortalecem a integração ensino-serviço e comunidade, além de contribuir no fortalecimento do trabalho em rede, potencializando as ações já desenvolvidas e propondo estratégias para fortalecer a articulação e a qualificação do cuidado, por meio da escuta acolhedora, sensível e qualificada aos cuidadores.

Desse modo, o processo de cuidado do Projeto Escuta Solidária vem permitindo a ressignificação do cuidado ampliado com um olhar para o todo, potencializando o amor, a sabedoria e a troca de experiências, conhecimentos e/ou saberes de vida. Assim, espera-se que esse processo de cuidar seja contínuo e aplicado em vários espaços e momentos das novas dimensões do viver.

O estudo contribui para a reflexão acerca da importância da escuta qualificada realizada pelo enfermeiro, como instrumento básico para o cuidar, como forma de humanização, responsabilização e comprometimento com as necessidades do outro, considerando sua singularidade que nesse momento se faz necessário ao cuidador, que por vezes não é colocado como um dos principais agentes de viabilização dos cuidados ao idoso, que se caracteriza como primordial ou único nesse momento de pandemia.

\section{CONSIDERAÇÕES FINAIS}

A pessoa cuidadora é protagonista da manutenção de cuidados à população idosa. O panorama atual de pandemia exacerba a carga de trabalho vivenciada pela mesma, expondo-a a situações de maior vulnerabilidade física, emocional e psicossocial. Acolhê-la por meio da escuta qualificada é uma ação de enfermagem necessária e urgente, de forma a detectar e enfrentar problemas e garantir a qualidade e continuidade dos cuidados aos idosos.

A escuta qualificada, com olhar ampliado também para os cuidadores dos idosos, promove o apoio emocional através do "ouvir" de forma ética, acolhedora e empática, criando e mantendo o vínculo seguro, no sentido de fortalecê-los, melhorando a sua harmonização pessoal e a sua qualidade de vida.

\section{AGRADECIMENTO}

Ao Departamento Científico de Enfermagem Gerontológica da ABEn Nacional.

\section{REFERÊNCIAS}

1. Organização Pan-Americana da Saúde [OPAS]. Folha informativa - COVID-19 (doença causada pelo novo coronavírus). [Internet] 2020. Disponível em: https://www.paho.org/bra/index.php?option=com_content\&view=article\&id=6101:covid $19 \&$ Itemid=875. 
2. Maia ER, Gonçalves Junior J, Pimentel JVC, Rolim Neto ML, Pagliuca LMF. Functional disability in the elderly people: systematic review. HealthMED - Volume 11 / Number 2 / 2017 file:///D:/Downloads/HealthMED_ Functionaldisabilityintheelderlypeoplesystematicreview.pdf

3. Argenta C, Nunes DP, Hammerschmidt KSA, Niwa LMS, Souza PA, Melo POC. Distanciamento social do idoso saudável durante a pandemia COVID-19: possibilidades e desafios. Enfermagem gerontológica no cuidado ao idoso em tempos da COVID-19.Série enfermagem e pandemias. Associação Brasileira de Enfermagem.--Brasília, DF : ABen/DCEG, 2020. 74 p.: il., color.; (Série enfermagem e pandemias). Acesso em: 20/06/2020. Disponívem em: http://www.abennacional.org.br/site/wp-content/uploads/2020/05/E-BOOK-GERONTO.pdf

4. Camarano MA. Nota Técnica $N^{\circ} 64$ - Cuidados para a população idosa e seus cuidadores: demandas e alternativas. Diretoria de Estudos e Políticas Sociais. Instituto de Pesquisa Econômica Aplicada IPEA. Rio de Janeiro. abril de 2020. Acesso em: 12/06/2020. Disponível em: http://repositorio.ipea.gov.br/bitstream/11058/9934/1/NT_64_Disoc_Cuidados\%20para\%20 a\%20populacao\%20idosa\%20e\%20seus\%20cuidadores.pdf

5. Giacomin KC, Duarte YAO, Camarano AA, Nunes DP, Fernandes D. Cuidados e limitações funcionais em atividades cotidianas - ELSI-Brasil. Rev Saúde Pública. 2018;52 Supl 2:9s. Doi.org/10.11606/S1518-8787.2018052000650

6. Nunes DP, Brito TRP, Duarte YAO, Lebrão ML. Cuidadores de idosos e tensão excessiva associada ao cuidado: evidências do Estudo SABE. Rev. Bras. Epidemiol. 2018b; 21(SUPPL 2): E180020.SUPL.2 https://doi.org/10.1590/1980-549720180020.supl.2

7. Lima-Costa MF, Peixoto SV, Malta DC, Szwarcwald CL, Mambrini JVM. Cuidado informal e remunerado aos idosos no Brasil (Pesquisa Nacional de Saúde, 2013). Rev. Saúde Pública [online]. 2017, vol.51, suppl.1 http://dx.doi.org/10.1590/ s1518-8787.2017051000013

8. Waldow V.R. Cuidado humano: o resgate necessário. Porto Alegre (RS): Sagra Luzzatto; 1998.

9. Hedler HC, Faleiros VP, Santos MJS, Almeida MAA. Representação social do cuidado e do cuidador familiar do idoso R. Katálysis, Florianópolis, 2016. v. 19, n. 1, p. 143-153 jan./jun. http://dx.doi.org/10.1590/1414-49802016.00100015.

10. Hammerschmidt KS de A, Santana RF. Saúde do idoso em tempos de pandemia Covid-19. Cogitare enferm. [Internet]. 2020. http://dx.doi.org/10.5380/ce.v25i0.72849

11. Ribeiro AP, Moraes CL, Sousa ER, Giacomin K. O que fazer para cuidar das pessoas idosas e evitar as violências em época de pandemia? ABRASCO, 2020. Acesso em 17/06/2020. Disponível em: https://www.abrasco.org.br/site/ noticias/o-que-fazer-para-cuidar-das-pessoas-idosas-e-evitar-as-violencias-em-epoca-de-pandemia-artigo/48196/

12. Yavo IS, Campos EMP. Cuidador e cuidado: o sujeito e suas relações no contexto da assistência domiciliar. Psicol. Teor. Prat. vol.18 no.1 São Paulo abr. 2016. Acesso em: 05/06/2020. Disponível em: http://pepsic.bvsalud.org/scielo.php?script=sci_ar ttext\&pid=S1516-36872016000100002.

13. Souza S, Camacho ACLF, Joaquim FL, Santo FHE. O planejamento do autocuidado para o cuidador de idosos: revisão integrativa. Rev Enferm UFPE on line. Recife, 10(5):1866-72, maio, 2016. http://DOI:10.5205/ reuol.9003-78704-1-SM.1005201636

14. Perseguino MG, Horta ALM, Ribeiro CA. A família frente a realidade do idoso de morar sozinho. Rev Bras Enferm [serial on the internet]. 2017 ;70(2):235-41. https://doi.org/10.1590/0034-7167-2016-0398 